\title{
Comparison of Personal and Area Sampling Strategies in Assessing Workers' Exposure to Vinyl Chloride Monomer
}

\author{
C.-L Du, C.-C. Chan, J.-D. Wang \\ Institute of Occupational Medicine and industrial Hygiene, College of Public \\ Health, National Taiwan University, No. 1, Sec. 1, Jen-Ai Road., Taipei, Taiwan, \\ Republic of China
}

Received: 10 June 1995/Accepted: 7 September 1995

Vinyl chloride monomer (VCM) is the main raw material in manufacturing polyvinyl chloride (PVC) resins. Several studies have reported that exposures to VCM are associated with various health effects, such as, hepatomegaly, splenomegaly, Raynaud's phenomenon, scleroderma, and acroosteolysis (Veltman et al., 1975). In recent 20 years, several epidemiological studies have shown that PVC workers have higher risks in developing certain cancers, such as liver angiosarcoma, brain tumor and lung cancer (Wong et al., 1991; Wu et al., 1977; Heldaas et al., 1984). Accordingly, worker's exposure limits to VCM have been greatly lowered since 1975 worldwide. Taiwan is one of the major production centers for PVC in the world, which currently produces 1/10 of PVC resins in the world. The VCM's health effects for workers in the PVC manufacturing industries in Taiwan, however, are not well documented until 1989 when our institute first performed health check-ups in 5 factories. A total of 210 workers were given the examinations of hand X-ray, indocyanine green (ICG) retention test, and liver sonography by our health surveillance team. Among them, 20 workers were diagnosed as hand marginal acroosteolysis. Higher ICG retention rates, prevalence of fatty liver and splenomegaly were also found for these workers (Wu and Wang, 1991; Wang et al., 1991). Unfortunately, we were unable to carry on measurements of VCM exposures of these workers at that time. In this study, sampling and analytic methods for VCM were developed and field sampling were carried out in order to estimate these workers' current VCM exposures. Both personal and area monitoring methods are applied in the field to compare their suitability in characterizing worker's VCM exposures. In addition, preliminary models to retrospectively construct cumulative personal exposures were proposed.

\section{MATERIALS AND METHODS}

The field sampling was performed in five PVC-manufacturing factories, which mainly used batch-type suspension method for PVC polymerization in their manufacturing processes. As indicated in Table 1, there are about 75-149

$\overline{\text { Correspondence }}$ to: J.-D. Wang 
employees, 6-31 reaction tanks and 105,600 - 540,750 tons of PVC yearly production rates in these five factories. The air sampling strategy included an extensive area and personal monitoring by using both active and passive samplers in the first year. The air monitoring in the second year only measured areas with high concentrations and persons with high exposures identified in the first year. Only passive samplers were used in the second year. After a comprehensive walk-through survey and discussion with industrial hygiene personnel of individual factories, we have classified the manufacturing process into 15 exposure zones for different unit operations to be monitored. The samplers of area sampling were placed in the center of each zone at a height of $1.2 \mathrm{~m}$ above ground.

Table 1. Basic data of five PVC factories. *Polymerization method: "S"- suspension "B"- bulk, "E"- emulsification

\begin{tabular}{lccccc}
\hline $\begin{array}{l}\text { factory } \\
\text { name }\end{array}$ & $\begin{array}{c}\text { no. of } \\
\text { workers }\end{array}$ & $\begin{array}{c}\text { no. of } \\
\text { tanks }\end{array}$ & $\begin{array}{c}\text { tank } \\
\text { volume }\left(\mathrm{M}^{3}\right)\end{array}$ & $\begin{array}{c}\text { polymerization } \\
\text { method* }\end{array}$ & $\begin{array}{c}\text { PC production } \\
\text { (Tons/year) }\end{array}$ \\
\hline A & 138 & 2 & 15 & $\mathrm{~S}$ & 105,000 \\
& & 18 & 20 & $\mathrm{~S}$ & \\
& & 10 & 20 & $\mathrm{E}$ & \\
B & \multirow{2}{*}{149} & 16 & 30 & $\mathrm{~S}$ & 540,750 \\
& & 7 & 130 & $\mathrm{~S}$ & \\
& & 6 & 50 & $\mathrm{~B}$ & \\
C & 74 & 6 & 130 & $\mathrm{~S}$ & 210,000 \\
D & 73 & 12 & 28 & $\mathrm{~S}$ & 105,600 \\
& & 8 & 10 & $\mathrm{~S}$ & \\
$\mathrm{E}$ & 75 & 12 & 20 & $\mathrm{~S}$ & 126,000 \\
& & 6 & 60 & $\mathrm{~S}$ & \\
\hline
\end{tabular}

For comparison and construction of an exposure model, samples were also collected from worker's breathing zones for 15 different job titles. The personal sampling was carried out for all workers with reaction tank-related tasks, such as tank supply, PVC relief, and tank cleaning. But for workers with other job titles, representative personal samples were collected through random sampling. Two consecutive air samples were collected mainly by passive samplers for 4-6 hours in order to monitor air concentrations over full shifts at each sampling unit. The 3M (St. Paul, Minnesota, U.S.A) badge-typed passive samplers with a sampling rate of $40 \mathrm{cc} / \mathrm{min}$ were used. In order to compare monitoring results of passive samplers to those of the US NIOSH (National Institute of Occupational Safety and Health) recommended active sampling method, a total of 30 pairs of air samples were concurrently collected by both active and passive samplers. The active sampler contained an activated charcoal tube $(400 / 200 \mathrm{mg}$ ) and a lowflow pump of $50 \mathrm{cc} / \mathrm{min}$. All samplers were capped and immediately stored in a $4^{\circ} \mathrm{C}$ refrigerator after sampling. The compound of VCM was then extracted with 


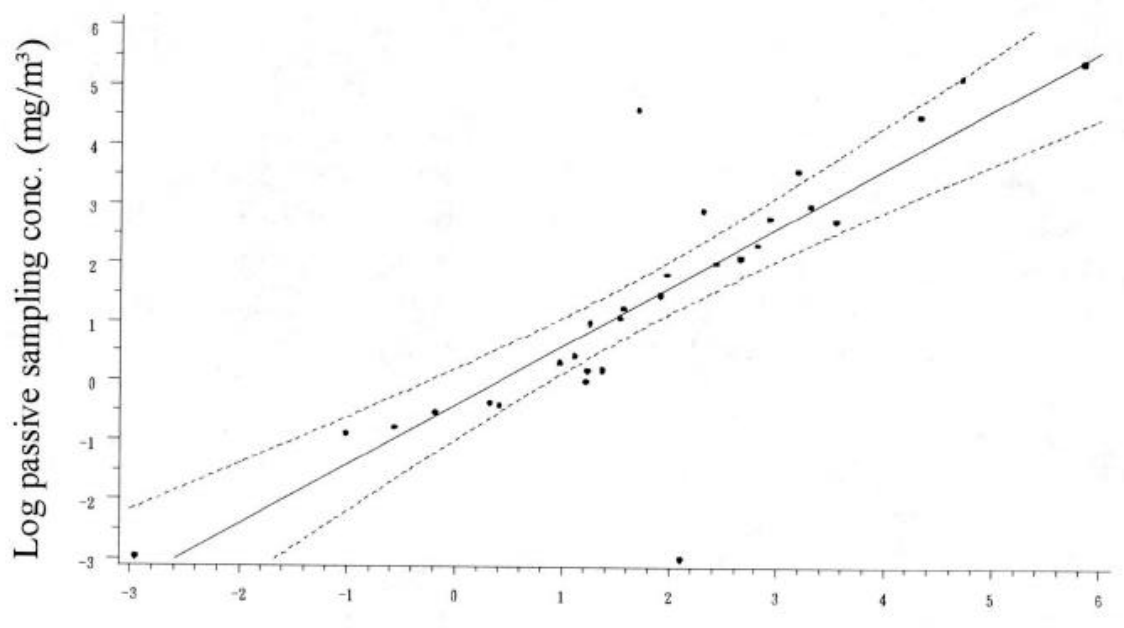

Log active sampling conc. $\left(\mathrm{mg} / \mathrm{m}^{3}\right)$

Figure1. Comparison of active and passive sampling results. Sample size=30, R=0.89.

carbon disulfide $\left(\mathrm{CS}_{2}\right.$ and analyzed within two weeks after sampling. The analytic instrumentsincluded a gas chromatography with flame ionization detector (GC-FID). The 30m fused silica column (WCOT, DB-1, film $3.0 \mu \mathrm{m}$, $\mathrm{ID}=0.53 \mathrm{~mm}$ ) was used to separate VCM from other compounds. The analytical condition included a carrier gas flow rate at $15 \mathrm{ml} / \mathrm{min}$ and a temperature program of injector at $200{ }^{\circ} \mathrm{C}$, detector at $250{ }^{\circ} \mathrm{C}$, and oven at $50{ }^{\circ} \mathrm{C}$ for $1 \mathrm{~min}$ and $5{ }^{\circ}$ $\mathrm{C} / \mathrm{min}$ programmed increase till $70{ }^{\circ} \mathrm{C}$. The amount of $\mathrm{VCM}$ was quantified by using n-hexane as an internal standard and VCM's retention time. The analytical method's desorption rate was found to be around $110 \%$ and limit of detection (LOD) was $129.5 \mu \mathrm{g} / \mathrm{m}^{3}$. The VCM concentration of blank samples (10\% of total samples) were all found to be less than LOD. For the 16 field duplicate samples, their relative standard deviation (RSD) in VCM measurements was found to be less than $3 \%$.

In order to relate area concentrations to VCM production and work practices, the number of tank openings and cleanings was documented by the field sampling team. The worker's time-activities during the sampling period were also recovered by a data sheet in order to estimate the time-weighted average personal exposures from area air monitoring data.

\section{RESULTS AND DISCUSSION}

Passive sampler's performance was found to be as good as active samplers in measuring VCM in the workplace. As indicated in Figure 1, there was a good 
Table 2. The area VCM concentrations in five PVC-manufacturing factories.

LOD: limit of detection $\left(129.5 \mu \mathrm{g} / \mathrm{m}^{3}\right.$ in this study)

\begin{tabular}{lcccc}
\hline sampling site & $\begin{array}{c}\text { sample } \\
\text { size }\end{array}$ & $\begin{array}{c}\text { mean } \\
\left(\mathrm{mg} / \mathrm{m}^{3}\right)\end{array}$ & $\begin{array}{c}\text { median } \\
\left(\mathrm{mg} / \mathrm{m}^{3}\right)\end{array}$ & $\begin{array}{c}\text { range } \\
\left(\mathrm{mg} / \mathrm{m}^{3}\right)\end{array}$ \\
\hline outside reaction tank & 4 & 296.30 & 86.25 & $6.19-1009.32$ \\
reaction tank farm & 18 & 13.60 & 9.97 & $0.18-110.59$ \\
VCM recovery & 9 & 9.25 & 5.46 & $0.85-33.39$ \\
VCM shipping & 3 & 5.98 & 7.38 & $0.85-9.71$ \\
VCM storage tanks & 6 & 4.97 & 3.03 & $0.60-14.25$ \\
stripper & 12 & 3.86 & 1.68 & $<\mathrm{LOD}-18.62$ \\
waste water treatment & 7 & 3.37 & 3.32 & $0.83-6.73$ \\
drier & 11 & 2.62 & 1.55 & $<\mathrm{LOD}-7.17$ \\
control room(inside) & 6 & 2.15 & 1.48 & $0.57-5.13$ \\
control room(outside) & 7 & 1.71 & 0.91 & $0.18-4.07$ \\
PVC warehouse & 17 & 1.66 & 1.79 & $<\mathrm{LOD}-5.96$ \\
factory fencing & 3 & 1.66 & 0.85 & $<$ LOD-3.34 \\
additive preparation & 6 & 1.61 & 0.78 & $0.57-4.07$ \\
administrative office & 4 & 0.65 & 0.67 & $<$ LOD-1.27 \\
plastics pallet making & 1 & $<\mathrm{LOD}$ & $<\mathrm{LOD}$ & $<\mathrm{LOD}$ \\
\hline
\end{tabular}

Table 3. The personal TWA concentrations of VCM in various jobs of five PVC manufacturing factories. *tank cleaner: measured on a short-term task lasting for only 15-40 minutes.

\begin{tabular}{lcccc}
\hline job names & $\begin{array}{c}\text { sample } \\
\text { size }\end{array}$ & $\begin{array}{c}\text { mean } \\
\left(\mathrm{mg} / \mathrm{m}^{3}\right)\end{array}$ & $\begin{array}{c}\text { median } \\
\left(\mathrm{mg} / \mathrm{m}^{3}\right)\end{array}$ & $\begin{array}{c}\text { range of TWA } \\
\left(\mathrm{mg} / \mathrm{m}^{3}\right)\end{array}$ \\
\hline tank supplier & 9 & 659.67 & 23.70 & $5.70-3677.80$ \\
PVC reliever & 10 & 153.07 & 47.92 & $1.04-825.69$ \\
tank cleaner* & 14 & 95.57 & 69.15 & $0.36-341.88$ \\
VCM unloading operator & 2 & 12.56 & 12.56 & $10.23-14.97$ \\
safety \& health specialist & 4 & 12.04 & 1.74 & $1.19-22.87$ \\
foreman & 4 & 9.04 & 6.89 & $1.84-20.59$ \\
stripper operator & 3 & 4.51 & 3.37 & $2.33-7.82$ \\
VCM recovery operator & 5 & 4.38 & 4.48 & $0.88-5.93$ \\
control room operator & 8 & 4.01 & 3.47 & $1.04-10.02$ \\
field supervisor/manager & 6 & 3.42 & 3.47 & $1.19-7.95$ \\
general office personnel & 4 & 3.34 & 2.56 & $<$ LOD-8.18 \\
maintenance & 3 & 2.69 & 1.76 & $0.85-5.49$ \\
dryer operator & 6 & 1.84 & 1.48 & $<$ LOD-4.25 \\
bagger and trucker & 5 & 0.93 & 1.09 & $<$ LOD-1.58 \\
gatekeeper & 2 & 0.93 & 0.93 & $<$ LOD-1.86 \\
\hline
\end{tabular}


correlation in the measuring results for 30 sets of passive and active samplers placed side by $\operatorname{side}(\mathrm{R}=0.89)$. Such correlation was even better for area sampling application $(\mathrm{R}=0.99)$ than for personal sampling application $(\mathrm{R}=0.83)$. The good agreement between passive and active samplers is understandable because the environmental conditions were favorable for passive samplers in these plants during the sampling period, which were $0.1-1.7 \mathrm{~m} / \mathrm{s}$ wind velocity and $70-83 \%$ of relative humidity. Therefore, the validity of VCM data reported in this study is compatible to the measurements using the US NIOSH method.

As indicated in Table 2, distinct differences in VCM concentrations were found among 15 different operation units in these PVC manufacturing plants. In general, VCM concentrations decreased as the operational units were farther away from the reaction tanks. The three highest mean VCM concentrations were in the units of areas outside reaction tanks $\left(296.30 \mathrm{mg} / \mathrm{m}^{3}\right)$, reaction tank farm zones (13.60 $\mathrm{mg} / \mathrm{m}^{3}$ )and VCM recovery zones. The moderately high VCM concentrations in the units were like VCM shipping $\left(5.98 \mathrm{mg} / \mathrm{m}^{3}\right)$, VCM storage tanks $\left(4.97 \mathrm{mg} / \mathrm{m}^{3}\right.$ stripper $\left(3.86 \mathrm{mg} / \mathrm{m}^{3}\right.$, waste water treatment $\left(3.37 \mathrm{mg} / \mathrm{m}^{3}\right)$, and drier areas $(2.62$ $\left.\mathrm{mg} / \mathrm{m}^{3}\right)$. The VCM concentrations were all less than $2.5 \mathrm{mg} / \mathrm{m}^{3}$ in the other operational units. The two-order decrease in VCM concentrations from reaction tanks to other operational units within workplace can be attributable to VCM's high volatility (vapor pressure $=2,943 \mathrm{mmHg}, 25{ }^{\circ} \mathrm{C}$ ). A wide variation in $\mathrm{VCM}$ measurements for individual operational units simply reflected the difference in reaction tank-opening frequencies during the sampling periods. In comparisons to VCM measurements reported in previous studies, the concentrations seemed to be lower in the current study (Myra 1976).

The personal TWA exposures to VCM in 15 different job titles were list in Table 3. The three highest mean TWA exposures were found to be the tank supplier $\left(659.67 \mathrm{mg} / \mathrm{m}^{3}\right)$, the PVC reliever $\left(153.07 \mathrm{mg} / \mathrm{m}^{3}\right)$, and the tank cleaner $(95.57$ $\left.\mathrm{mg} / \mathrm{m}^{3}\right)$. Their high VCM exposures apparently were due to a more direct contact with VCM during opening or cleaning of reaction tanks in their work practices. The mean TWA exposures were mostly higher than $2.5 \mathrm{mg} / \mathrm{m}^{3}$ for the jobs in these plants except for workers in drying operation, bagging, trucking, and gate keeping. From the results of in-field observations, the generally high exposures for most job titles were partly contributed by excess VCM emissions from reaction tank opening. The reaction tanks were usually opened before the recovery process had completed in these plants. In general, the variation in personal exposures were in agreement with fluctuation in area concentrations. In comparisons to VCM exposure limits and guidelines, such as Permissible Exposure Limit by Taiwan's Council of Labor Affairs $\left(25 \mathrm{mg} / \mathrm{m}^{3}\right)$ and ACGIH's TLV $\left(2.5 \mathrm{mg} / \mathrm{m}^{3}\right)$, the workers in this study seemed to have relatively high VCM exposures. Among 75 workers, there were 17 workers (23\%) with TWA exposures greater than $25 \mathrm{mg} / \mathrm{m}^{3}$, and 44 workers (59\%) with TWA exposures greater than $2.5 \mathrm{mg} / \mathrm{m}^{3}$. However, these exposures were lower than most exposure data in previous studies of which acute VCM-related effects were 


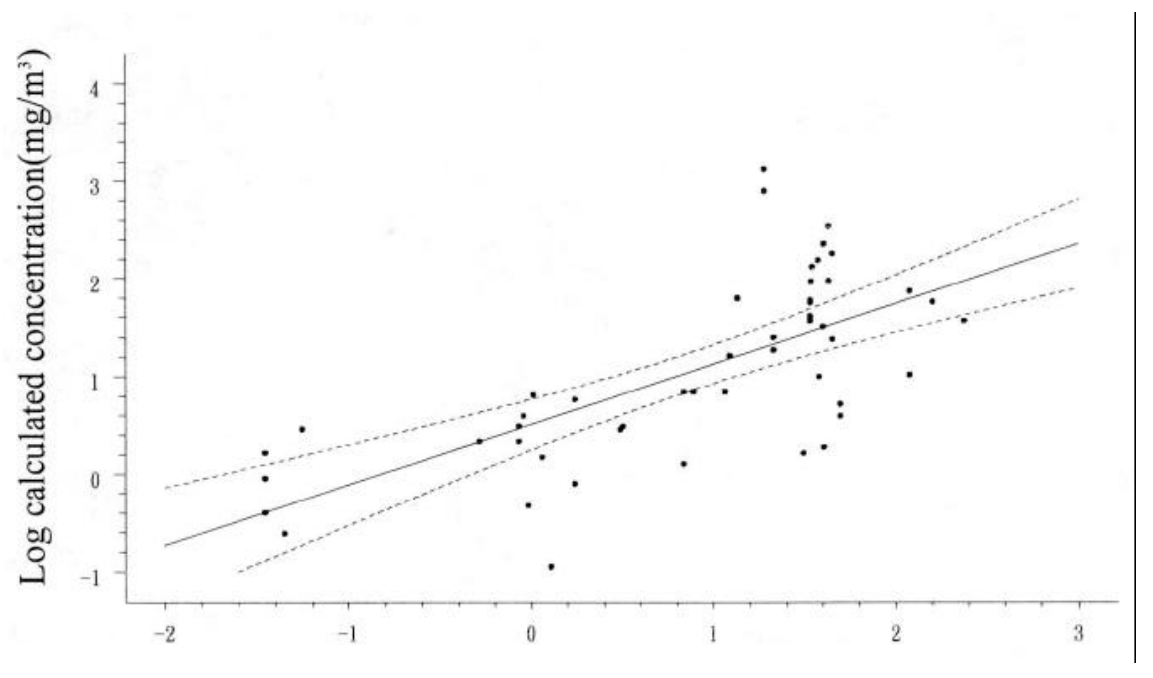

Log measured concentration $\left(\mathrm{mg} / \mathrm{m}^{3}\right)$

Figure2. Comparison of personal exposure. The 49 sets of measured and calculated data were compared using SAS regression model. The regression equation is $\log ($ VCMcalculated $)=0.76 \log ($ VCMmeasured $)+0.08 ;$ R-square $=0.47$.

frequently reported (Spirtas et al., 1975). The modification in PVC manufacturing processes, such as stripping of VCM from polymerization tank before opening and low-scale techniques in modern plants, is believed to be the main reason of reduction in worker's and area exposures,

Personal VCM exposures can be either measured by personal samplers directly (VCMmeasured) or estimated indirectly from area sampling results, By combining individual worker's time-activity patterns with mean area concentrations in various operational units, TWA personal VCM exposures can be indirectly calculated (VCMcalculated). A moderate agreement between VCMmeasured and VCMcalculated was found for 49 pairs of simultaneously measured personal and area VCM concentrations. As indicated in Figure 2, the regression equation for them is $\log (\mathrm{VCMcalculated})=0.76 \log$ (VCMmeasured ) +0.08 , with an R-square equals to 0.47 . The VCM concentrations in the equation were all logrithmatically transformed in order to meet the normal distribution requirement for regression analysis. The equation can only be applied to VCMmeasured, ranging from $0.78 \mathrm{mg} / \mathrm{m}^{3}$ to $22.80 \mathrm{mg} / \mathrm{m}^{3}$. For assessing personal cumulative exposures in the future, the indirect method seems applicable to PVC plants where area measurements were available and personal exposures were less than $25 \mathrm{mg} / \mathrm{m}^{3}$.

For extremely high exposure tasks, such as tank suppliers, where high area concentrations were difficult to measure, the indirect method of exposure was not 


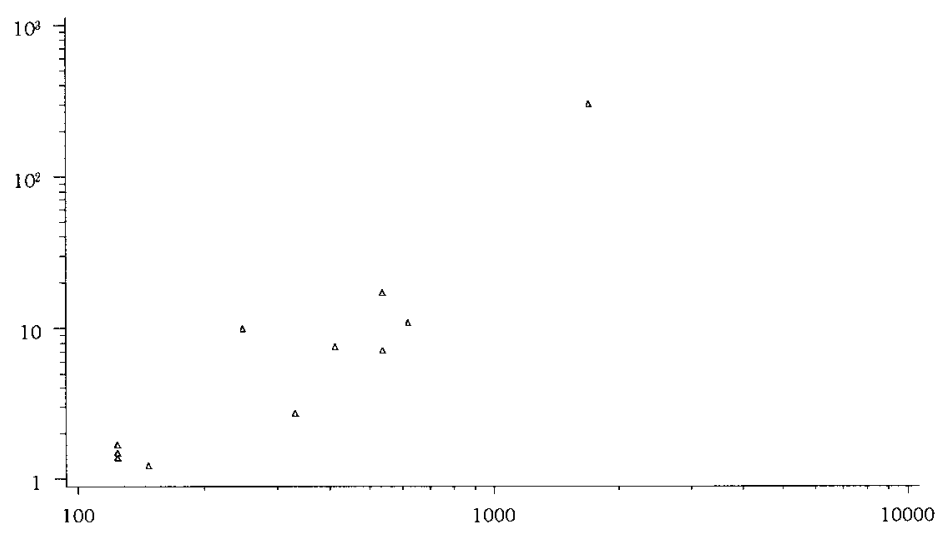

\section{measured personal exposure $\left(\mathrm{mg} / \mathrm{m}^{3}\right)$}

Figure 3 Association of measured personal exposure of tank suppliers

(VCMmeasured) with the VCM emission (VCMemitted) based on mass-

-balance estimation, amount is compared to measured exposure concentration

The regression equation is $\log ($ VCMmeasured $)=2.59+0.029 *$

(VCMemitted), $\mathrm{p}=0.0001$, sample size $=11$, adjusted R-square $=0.875$.

feasible. For tank suppliers, their VCM exposures were mainly from periodical openings of reaction tanks in the manufacturing process. The information about average VCM concentrations in reaction tank's outlets (VCMtank), the frequencies of tank opening, and the volume of tanks became useful in modeling high exposuregroups. An integrated amount of VCM emission during a workshift (VCMemitted) can, therefore, be calculated by multiplying the above three parameters together. In this study, the VCMtank was assumed to be about $4480 \mathrm{mg} / \mathrm{m}^{3}$, as carefully estimated by our Environment Protection Agency. As indicated in Figure 3, for tank suppliers a good correlation exists for VCMemitted and VCMmeasured with regression equation as $\log$ (VCMmeasured) $=2.59+0.029$ (VCMemitted), adjusted R-square $=0.875$

In order to construct worker's cumulative exposures retrospectively by indirect method, the area concentrations must be estimated as accurate as possible. Since the tank-opening process is the main emission sources of VCM, a predictive model based on it becomes necessary for an accurate estimation of area concentrations. A multiple regression model was applied to estimate the area VCM concentrations, using VCMemitted, average distance away from the main emission sources $(\mathrm{m})$, other minor emission sources and wind velocity as independent variables. The main emission sources were areas where reaction tanks located. The minor emission sources are leakage from manufacturing 
processes other than reaction tanks, such as areas of VCM recovery or storage. As summarized in Table 4, the results of backward regression indicated that the term of $\left(\mathrm{VCMemitted} / \mathrm{m}^{2}\right.$ ) was the only significant variable in predicting area concentrations in the best fitted models. The regression equations are: $\mathrm{Y}=0.86$ $\left(\mathrm{VCMemitted} / \mathrm{m}^{2}\right)+1.49$ with an R-square $=0.38$ for outdoor areas; $\mathrm{Y}=1.10$ $\left(\right.$ VCMemitted $\left./ \mathrm{m}^{2}\right)+0.84$ with an R-square $=0.21$ for the whole (indoor and outdoor) areas, $\mathrm{Y}$ is the logrithmatically transformed area VCM concentration measured in the study. Apparently, the model was better fitted for outdoor microenvironments than for indoor micro- environments. This model can be applied to all batch-type manufacturing plants in different time periods except for tank supplier, PVC reliever, and tank cleaner, of whom the exposure usually exceeded $25 \mathrm{mg} / \mathrm{m}^{3}$ TWA.

Table 4. Regression models and their parameters for predicting area VCM concen-trations using SAS backward regression procedure. The dependent variable is area concentration taken outdoors and/or indoors and logrithmatically transformed(in $\log \mathrm{mg} / \mathrm{m}^{3}$ ). Figures in parentheses show the standard error(S.E). *non-significant for $\mathrm{p}<0.01$.

\begin{tabular}{|c|c|c|c|c|c|c|}
\hline $\begin{array}{l}\text { location } \\
\text { of } \\
\text { sampling }\end{array}$ & $\begin{array}{c}\text { no. of } \\
\text { samples }\end{array}$ & $\begin{array}{c}\text { significant } \\
\text { variable }\end{array}$ & $\begin{array}{c}\text { regression } \\
\text { coefficient } \\
\text { (S.E) }\end{array}$ & $\begin{array}{c}\text { intercept } \\
\text { (S.E) }\end{array}$ & & $\mathrm{p} \mathrm{va}$ \\
\hline $\begin{array}{l}\text { outdoors } \\
\text { only }\end{array}$ & 28 & VCMemitted $/ \mathrm{m}^{2}$ & $\begin{array}{c}0.86 \\
(0.21)\end{array}$ & $\begin{array}{c}1.49 \\
(0.19)\end{array}$ & 0.38 & $p<0.01$ \\
\hline $\begin{array}{l}\text { outdoors+ } \\
\text { indoors }\end{array}$ & 49 & VCMemitted $/ \mathrm{m}^{2}$ & $\begin{array}{c}1.10 \\
(0.30)\end{array}$ & $\begin{array}{c}0.84 \\
(0.29)^{*}\end{array}$ & 0.21 & $\mathrm{p}<0.01$ \\
\hline
\end{tabular}

The PVC manufacturing workers' current VCM exposures are still relatively high in Taiwan. Considering possible higher exposures in the past, there is a concern for these workers' potential adverse health effects, More extensive and routine VCM monitoring in the workplaces is highly recommended. For extremely high exposure groups, such as tank suppliers, the requirement of compulsory use of respiratory protection devices is urgently recommended. The area VCM concentrations in the workplaces can be reasonably estimated from emission data, which are usually available in PVC manufacturing plants. By combining this model with work schedule data, individualized personal VCM exposures can be retrospectively reconstructed indirectly. More research on this exposure reconstruction issue is also highly recommended in order to precisely evaluate the health risks of occupational exposure to VCM.

Acknowledgments. We owe great debt to Ms. Chang Chin Yuan of Industrial Technology Research Institute for her help in developing the analytic method of VCM. Thanks also go to staffs and students of the Institute of Occupational Medicine and Industrial Hygiene of National Taiwan University for their help in 
performing field VCM sampling. The study is granted by National Science Council of Taiwan, NSC-81-0421-F-002-539-Z.

\section{REFERENCES}

Heldaas SS, Langard SL, Anderson A. Incidence of cancer among vinyl chloride and polyvinyl chloride workers. Br J Ind Med 1984, 41: 25-30

Myra Karstadt. PVC: Health implication and production trends. Environ Health Perspect, 1976,17: 107-115

Spirtas R, McMichael AJ, Gamble J, Vanert M. The association of vinyl chloride exposures with morbidity symptoms. Am Ind Hyg Assoc J, 1975:779-789

Veltman G, Lange CE, Jühe S, Stein G, Bachner U. Clinical manifestations and course of vinyl chloride disease. Ann New York Acad Sci, 1975, 246:6-17

Wang FS, Wu YG, Wang JD, Shyr DS (1991). Liver injuries among workers in PVC- manufacturing factories in Taiwan. Council of Labor Affairs, Taipei,Taiwan

Wong O, Whorton MD, Foliart DE, Ragland D. An industry-wide epidemiological study of vinyl chloride workers, 1942-1982. Am J Ind Med 1991, 20: 317-334

Wu W, Steenland K, Brown D, Wells V, Jones, J, Schulte P, Halperin W. Cohort and case-control analysis of workers exposed to vinyl chloride and polyvinyl chloride. Biochem Biophys Res Commun 1977, 76: 259-266

Wu YG, Wang JD (1991). Health survey of workers in five factories of PVC polymerization in Taiwan. Master thesis, college of public health, National Taiwan University, Taipei, Taiwan 